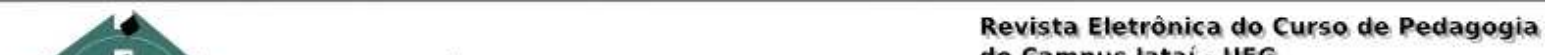 do Campus Jatai - UFG Ithmerarius Reflectionis
}

\section{UNIVERSIDADES CORPORATIVAS: UMA NOVA CONCEPÇÃO PARA O ENSINO SUPERIOR?}

\author{
Luciene Lima de Assis Pires*
}

\begin{abstract}
RESUMO: No presente artigo, analisa-se a estrutura e a expansão das universidades corporativas no Brasil. Em um primeiro momento apresenta-se o modelo seguido por essas universidades, que incorporaram a tradução da expressão corporate university utilizadas nos Estados Unidos, sem incorporarem a idéia brasileira de se trabalhar com ensino / pesquisa / extensão. Em seguida demonstra-se como estas instituições se estruturam e de que forma se organizam. Enumera-se as principais universidades corporativas já instaladas e o sistema de convênios que realizam com instituições conceituadas para assegurarem a certificação dos cursos.
\end{abstract}

Palavras-Chave: Ensino Superior - Universidade Corporativa - Universidade Acadêmica

ABSTRACT: In this paper, I analyze the structure and expansion of corporate universities in Brasil. Initially, I present the model followed by these universities, which have incorporated the expression "corporate university" used in the United States, leaving aside the Brazilian concept of gathering together teaching/research/extension. Then, I demonstrate how these institutions are structured and the way in which they organize the majoring. I list the main corporate universities already settled and the partnership system that they set with prestigious institutions in order to assure the certification of their courses.

Key-words: Higher Education - Corporate Universities - Universities

\section{Considerações iniciais}

A diversificação e diferenciação de cursos superiores no Brasil processaram-se no final do século XX e início deste século em várias frentes. Houve o agrupamento de faculdades em universidades, a criação de novos cursos, a expansão dos cursos tecnológicos. E, novo espaço surge e vem ganhando espaço na 'preparação' do trabalhador brasileiro. Um novo caminho que já está consolidado em países desenvolvidos, de forma mais específica nos Estados Unidos e que no Brasil, se instala com o aval do setor produtivo - as universidades corporativas.

\footnotetext{
Doutora em Educação pela UFG - Docente CEFET-GO /UNED - Jataí e UFG/CAJ lucieneapires@gmail.com
} 
O conceito de universidade corporativa é recente nos estudos no Brasil. Surgiu na segunda década de 1990, nos Estados Unidos, como um caminho para as empresas promoverem a formação de seus funcionários, fornecedores, colaboradores. Conhecer estas instituições tem sido uma constante em diferentes setores. Em junho de 2004, o Núcleo de Gestão Tecnológica da Universidade de São Paulo (PGT - USP) realizou um Seminário de Pesquisa, cujo tema foi "As universidades corporativas no contexto do ensino superior".

Outros estudos sobre estas instituições vêm sendo desenvolvidos no país e, dentre eles, merecem destaque os desenvolvidos por Alperstedt (2001, 2003), Bianchetti e Quartiero (2005), Braga (2004), Costa (2001), Éboli (1999), Embacher (2003a, 2003b), Ferreira (2002), Teixeira (2001). Apresenta-se aqui como estas instituições se organizam e o vínculo que possuem com o setor produtivo.

\section{As universidades corporativas e sua vinculação}

A disputa por mercados tem imposto às organizações uma situação de competitividade crescente, tendo levado à necessidade de repensarem a sua atuação e de estabelecerem novas definições na área dos negócios. Neste sentido, torna-se necessária, a obtenção e a seleção adequada de informações, o que pode representar o diferencial competitivo necessário para determinar vantagens competitivas para uma organização. Este é, segundo Alperstedt (2003), o caminho para a expansão das organizações corporativas. "O conhecimento está, portanto, se transformando no recurso que mais agrega valor aos negócios e, por conseguinte, à economia", diz ela. Esta perspectiva tem levado um número considerável de organizações a criarem formas alternativas de formação de pessoal, como forma de "ampliar as habilidades de seus recursos humanos, visando a continuidade da prestação de um serviço de qualidade para a empresa" (Idem). Há o aumento da demanda por serviços educacionais, que impulsiona a proliferação das, então denominadas, universidades corporativas.

A autora acrescenta que as mudanças aceleradas no mundo, a disseminação da informação, a pressão competitiva, a reação do mercado, a redefinição no mundo dos negócios, dentre outras 'forças', impõe às organizações a necessidade de se repensar a sua atuação, visto que "a agregação de informações selecionadas serve de base para a geração de conhecimento". E acrescenta que "o conhecimento está, portanto, se transformando no recurso que mais agrega valor aos negócios e, por conseguinte, à economia" (ALPERSTEDT, 2001, p. 5-6). Para ela, estas instituições têm como objetivo principal a "manutenção de 
empregados com elevado potencial de agregação de valor, representando uma fonte potencial de vantagens competitivas" (Idem, p. 7). E afirma ainda que o processo de aprendizagem deixou de ser apenas um valor agregado e transformou-se em uma estratégia de desenvolvimento organizacional fundamental, para garantir a sobrevivência da empresa (Idem, p. 28). Para ela, "na era do conhecimento, a dinâmica da mudança tecnológica exige um aprendizado constante e a atualização permanente durante a vida profissional" (Idem, p. $105)$.

Para esta autora, o conhecimento nas universidades corporativas, capaz de 'agregar valor', segue a tendência do 'mundo globalizado' e, citando Peterson \& Dill (1997), afirma que "a mudança do sistema educacional composto por instituições de ensino superior tradicionais para o 'setor do conhecimento superior' sugere um novo paradigma para as instituições de ensino superior tradicionais" (PETERSON \& DILL, 1997 apud ALPERSTEDT, 2001, p. 112). Segundo ela, há também uma "forte tendência de valorização das habilidades e competências dos indivíduos em paralelo à desimportância crescente atribuída à diplomas e certificados" (Idem, p. 151), que é a premissa básica do estudo por ela desenvolvido. Neste sentido, a autora afirma que a necessidade de aquisição e renovação do conhecimento é percebida por parte da empresa "de forma organizacional", e também por parte dos indivíduos que nela atuam "de modo individual", isto porque "as pessoas estão dispostas a desenvolver e aumentar seus estoques de conhecimento porque percebem as potenciais ameaças do ambiente sobre a passividade intelectual, abalando principalmente questões de segurança profissional. A ampliação do quantum de conhecimento aumenta as chances de alocação no mercado de trabalho" (Idem, p. 29). As universidades corporativas são, assim, percebidas como “agente de mudanças na organização' e possibilidades de se aumentarem as qualificações, conhecimentos e competências relacionadas ao cargo" e, para o empregado, é um incentivo, "uma possibilidade de incremento de seu curriculum, cuja validade não se restringe àquele emprego" (Idem, p. 56).

Fica claro, nas definições acima apontadas, a concepção de conhecimento como algo estanque, quantificável, algo capaz de se estocar para ser utilizado quando solicitado, além do discurso da empregabilidade - só fica desempregado quem quer, quem não procura aprimorar seus conhecimentos. É esta a perspectiva das empresas. Embora não haja, no Brasil, estudos específicos que analisem a oferta de cursos para empresas, por parte das instituições ditas tradicionais, Alperstedt cita estudos realizados nos Estados Unidos os quais apontam que, embora estejam em acordo com os objetivos pretendidos, isto não significa que os cursos ofertados pelas universidades tradicionais sejam satisfatórios. Afirma ainda, que eles "não são 
efetivos no provimento de programas gerenciais de desenvolvimento" havendo necessidade de "elos mais fortes entre desafios e realidades do trabalho, de novas abordagens de promoção do aprendizado e de programas focados nas necessidades das empresas", o que é resolvido com a criação das universidades pelas próprias empresas (2001, p. 34-41).

Ferreira (2002) também tece críticas às universidades ditas tradicionais, ao afirmar que há uma enorme distância entre o perfil ideal de um profissional e o aluno formado pelas faculdades, e que as empresas, devido à competitividade atual, não demandam muito tempo para formarem internamente os seus profissionais. Segundo ele, há um distanciamento entre o que se ensina na faculdade e as necessidades concretas do mercado, conseqüência da diferença de objetivos entre a escola e a empresa. As universidades corporativas "criam um novo parâmetro de formação profissional, bem diferente do existente no ensino superior [...] A universidade tenta dar uma formação generalista e as empresas querem um profissional formado mais rapidamente" (p. 4). As universidades corporativas, defende ele, querem desenvolver uma competência crítica e um diferencial adaptado a seus produtos desta forma: "antes, o aluno saía da universidade e a empresa levava quatro ou cinco anos para formar um funcionário de acordo com suas necessidades. Não dá mais para esperar todo esse tempo" (Idem). E as universidades convencionais deveriam, segundo ele, procurarem cada vez mais parcerias com as empresas, a fim de se criarem cursos que atendam às demandas específicas, podendo utilizar o know how que possuem e justifica esta afirmação citando o caso da parceria entre a Empresa Brasileira de Aeronáutica S.A (Embraer) e a Universidade do Vale do Paraíba (UNIVAP) para criação do Curso Superior Seqüencial em Tecnologia Aeroespacial que levou para a UNIVAP, como professores, os doutores do quadro da Embraer. "As corporativas desenvolvem um processo pedagógico acelerado, porém personalizado e flexível" (p.5), diz ele.

Nesta mesma linha de pensamento, Teixeira (2001) afirma que "não há um conceito único e universalmente válido de universidade, nem as funções são as mesmas em tempos e espaços diferentes. [...] a universidade se ajusta, não fixando-se somente em um único modelo” (p. 25). A autora defende que o modelo das corporativas é também universidade, pois "gera" um saber. No entanto, para ela não é um saber fundamentado na pesquisa, é "um saber que possibilite a expressão da emoção e do prazer, um saber comprometido com a igualdade, porque ela é a base da estrutura social e inerente à condição humana" (p. 25). Para esta autora, as universidades corporativas surgem em um momento de grandes mudanças na sociedade, na busca de qualificação profissional e atendem as empresas que precisam "sustentar a vantagem competitiva" (p. 29-30). 
Alperstedt (2001) define universidades corporativas como

Instituições criadas e vinculadas a empresas, voltadas para a formação de competências essenciais à organização que, cumulativamente, apresentem as seguintes características: estendam seus serviços educacionais, conforme o caso, a fornecedores, clientes, franqueados, outras empresas e a comunidade externa, não restringindo-os a seus empregados; estabeleçam parcerias com instituições de ensino superior, culminando com a validação dos créditos cursados e possibilidade de outorga de diplomas, ou que desfrutem da possibilidade de outorga de diplomas de forma independente (p. 20).

Diferentes questões surgiram em relação à denominação dada a estas universidades e, dentre elas, vale destacar as que se referem às semelhanças e/ou diferenças existentes entre as universidades corporativas e instituições de ensino superior tradicionais. Para Alperstedt (2003), ao se usar a expressão 'universidade corporativa', fez-se a tradução simples da expressão corporate university, bastante utilizada na literatura americana. Sabe-se que nela o uso do termo 'corporate' decorre do fato de que essas instituições estão ligadas a empresas, revelando que, "pelo menos a princípio, a prestação de serviços educacionais não constitui per se o seu objetivo fundamental". Por outro lado, a adoção do termo 'university' é utilizada pelos empresários atribuindo a estas instituições o 'status da academia'; buscando ainda "denotar uma seriedade de propósitos, em termos de comprometimento com os objetivos pretendidos" (Idem).

Também sobre esta relação entre as universidades corporativas e as universidades tradicionais, Teixeira (2001) diz que "na universidade em que se tem o monitor, os professores e coordenadores, assuntos diferentes são abordados, conduzindo o aluno a um futuro aperfeiçoamento. Mesmo com toda a bagagem que as universidades disseminam aos alunos, surge a necessidade de preparar as pessoas para atuarem em 'seu' negócio específico" (p. 26) o que, para a autora, as universidades tradicionais não fazem.

Sobre o uso da expressão universidade corporativa, Meister (1999) também se pronuncia e justifica que esta denominação abre, para as instituições envolvidas, a possibilidade de criação de uma marca para os seus programas educacionais, que resultarão em materiais didáticos a serem comercializados, o que representa a abertura de um novo espaço de investimento: o mercado educacional. Para Ferreira (2002), "a obtenção de uma nova fonte de renda também serve de elemento motivador para que as universidades corporativas passem a treinar os elementos que compõem a sua cadeira de valor. $\mathrm{O}$ licenciamento de programas para fornecedores e clientes tornou-se uma importante fonte de receita para as universidades corporativas que objetivam sua independência financeira" (p. 3). 
Além deste aspecto, o autor salienta que o "alinhamento entre os objetivos do negócio com os objetivos educacionais proporciona a geração de valor agregado efetivo para cada participante do processo" (p. 2). É preciso deixar claro que tanto Alperstedt como Meister reconhecem que a simples utilização do termo 'universidade' "não confere a essas instituições a mesma conotação que a palavra possui no sistema educacional". O modelo de universidade pautado no tripé ensino - pesquisa - extensão não é de forma alguma percebido nas 'corporativas'.

Para Alperstedt (2003), "a criação destes cursos formais pelas empresas, disponibilizados pelas universidades corporativas, não se restringe apenas à seara da administração e gerência; abrange a área de informática, de engenharia e outras áreas consideradas vitais para o tipo de negócio da empresa" Segundo ela, algumas universidades corporativas focam as competências como, por exemplo, desenvolvimento de qualidades de liderança e compreensão dos valores organizacionais. Outras enfatizam a aprendizagem horizontal, em que profissionais de marketing aprendem sobre tecnologia, por exemplo. E outras enfocam a aprendizagem vertical, promovendo o aprofundamento de conhecimentos e técnicas específicas. Essa autora afirma, ainda, que combinações entre esses tipos são bastante freqüentes (Idem). Para ela, o objetivo da empresa é que o empregado seja mais produtivo, esta é a razão de se investir nele, "proporcionando-lhe o desenvolvimento de habilidades técnicas, humanas e conceituais" (ALPERSTEDT, 2001, p. 26) ou "o desenvolvimento de posturas e não apenas conhecimento técnico e instrumental" (FERREIRA, 2002, p. 2).

\section{A formação nas universidades corporativas}

Segundo os defensores das universidades corporativas, um novo paradigma sobre o conceito de universidade está se consolidando. “A associação da palavra 'universidade' com a imagem de campus, edifícios, reitores e professores passa longe da idéia da versão de universidade corporativa na visão empresarial. Trata-se mais de um processo vivo com todos os níveis da empresa envolvidos na aprendizagem” (p. 30, grifo meu). As universidades existentes, que primam por manter a construção de um saber fundamentado na pesquisa, são consideradas estruturas burocráticas, provavelmente um processo morto.

Fazendo um estudo de caso da Universidade Embraer, Ferreira (2002) afirma que as empresas que necessitam de mão-de-obra altamente especializada encontram, no investimento nas 'corporativas', o caminho para a redução de custos na qualificação de seus profissionais o que representa em contra partida 'diferenciais competitivos sustentáveis'. Para ele, as empresas, para atrair e reter talentos e atender à 'gestão do capital humano', reagem à 
competitividade crescente, "quebrando paradigmas tradicionais e trazendo para si a responsabilidade da coordenação do aprendizado e da educação de seu Fator Humano, procurando suprir as deficiências do sistema educacional tradicional” (p. 2).

A questão da educação como capital humano é objeto de críticas de diferentes autores, e vale destacar, dentre eles Frigotto (2000). Para ele a educação alçada ao capital humano é uma esfera específica das teorias de desenvolvimento. "A idéia chave é de que a um acréscimo marginal de instrução, treinamento e educação, corresponde um acréscimo marginal de capacidade de produção" (p. 41). Há desta forma, a crença de que os investimentos em qualificação permitem a quantificação de um "determinado volume de conhecimentos, habilidades e atitudes adquiridas, que funcionam como potencializadoras da capacidade de trabalho e de produção" (FRIGOTTO, 2000, p. 41).

Este pressuposto, de que a educação é produtora da capacidade de trabalho deve, segundo Frigotto, suscitar uma questão básica: "como e que tipo de educação é gerador de diferentes capacidades de trabalho e, por extensão, da produtividade e da renda?". No entanto, nos estudos realizados sobre as universidades corporativas, percebe-se que as empresas desconsideram a qualificação recebida pelo profissional na rede 'convencional' de ensino, o que implica na criação de uma rede paralela, "um novo entrante no contexto do ensino superior", diz Alperstedt (2003).

Acreditando ser o caminho criticado por Frigotto o que deve ser percorrido pelas empresas, na qualificação de seus servidores, Ferreira (2002) mostra, no estudo feito na Universidade Embraer, que os resultados dos investimentos "não demoram a aparecer nos balanços da empresa, que passam a mostrar lucros substancialmente maiores" (p.1). Segundo ele, estudos desenvolvidos em 100 universidades corporativas americanas revelam que o retorno do investimento é bem maior do que ocorre em um treinamento tradicional. Se "para cada US\$ 1 usado em treinamento tradicional o retorno é de US\$ 0,50, no caso das universidades corporativas o retorno é US\$2" (p.3).

Pode-se afirmar que as empresas, devido à necessidade de investirem na formação de seus profissionais buscam, na alternativa das universidades corporativas, minimizarem os custos dos investimentos e criar novas fontes de lucro. Há uma demanda real de mais conhecimento e, para Frigotto,

Esta demanda real de mais conhecimento, mais qualificação geral, mais cultura geral se confronta com os limites imediatos da produção, da estreiteza do mercado e da lógica do lucro. No caso brasileiro, o atraso de um século, pelo menos, na universalização da escola básica é um dos indicadores do perfil anacrônico e opaco das nossas elites e um elemento cultural que potencia o 
descompasso do discurso da 'modernidade' e defesa da educação básica de qualidade, da ação efetiva destas elites (2000, p. 158).

Nas empresas, os gastos com a qualificação profissional são considerados investimentos com retorno garantido. Nos estudos realizados para a implantação da Universidade Embraer implantada em março de 2001 -, calculou-se que seriam gastos US $\$ 25,0$ milhões/ano com a contratação / manutenção de especialistas estrangeiros; com os investimentos na universidade corporativa nos anos posteriores haveria uma redução nas despesas com pessoal, na ordem de US\$ 5,0 milhões/ano.

Ao mesmo tempo em que são enumeradas características e defesas em prol das universidades corporativas, são também tecidas críticas à formação nas demais instituições de ensino superior. Alperstedt (2001), citando estudos realizados na América - Latina e do Norte - afirma que "as instituições de ensino superior são percebidas como exemplos proeminentes de organizações debilmente coesas ou frouxamente articuladas e cujos objetivos são vagos, ambíguos e conflitantes [...] em contraste com a percepção acerca de organizações corporativas, nas quais a estrutura organizacional é intensivamente voltada para o atendimento dos objetivos almejados, que por sua vez são bem definidos e claros" (p. 44-45). E acrescenta: "observa-se que a lógica institucional da universidade é diferente da lógica corporativa" (Idem).

Ora, a caracterização das universidades corporativas segue a lógica mercadológica, à qual as instituições consideradas por Alperstedt (2001) como 'tradicionais' tentam resistir. No entanto, a resistência a esta lógica não é sinônimo da não implantação de instituições 'especializadas por campo do saber'. Ao contrário pode-se afirmar que a criação das universidades corporativas no Brasil tem se dado de forma bastante rápida e voltadas para a formação de um 'capital intelectual'.

Depois de perceber que para se tornar mais competitiva no mercado uma empresa depende muito de seu capital intelectual, algumas companhias passaram a consolidar programas internos de treinamento e disponibilizar cursos de MBA e Pós-graduação nas chamadas Universidades Corporativas. Fazem isso por meio de parcerias com Instituições de Ensino Superior (IES), que se beneficiam pela atuação mais direta junto ao mundo dos negócios. Atualmente [2004], há uma média de 50 Universidades Corporativas no Brasil (EDUCAÇÃO CORPORATIVA, 2004).

A formação desse 'capital intelectual', via universidades corporativas, não é um fato novo; segundo Alperstedt (2001), em 1988, havia, nos Estados Unidos, cerca de 400 instituições desse tipo. Este número 'saltou’ para 1.000, em 1997, e para 2.000, em 1999. 
Outra comparação, feita por Alperstedt (2001), entre as universidades corporativas e o ensino superior tradicional diz respeito à origem dos investimentos. Segundo ela, as universidades corporativas estão atreladas a determinadas empresas e dependem do capital das mesmas, razão pela qual as UCs se vinculam, geralmente, a empresas de grande porte. Na tentativa de se diminuir os investimentos, são estabelecidas parcerias ou consórcios entre as empresas o que, segundo ela, demonstra que "mais importante do que a capacidade de investimento, é o comprometimento da alta administração com a necessidade de viabilizar a aprendizagem" (p. 59). No que se refere aos custos, a autora deixa claro também que as empresas preocupam-se com o trabalhador e com a sua qualificação e critica a estrutura das instituições de ensino superior tradicionais. E citando Moore (1997) afirma que "no que compete à questão do custo, as universidades corporativas são significativamente mais eficientes se comparadas às instituições de ensino superior tradicionais" (MOORE, 1997 apud ALPERSTEDT, 2001, p. 50). Mas salienta que esta comparação exige que se considerem economias de escala em um horizonte de tempo mais longo, e que se enfoque, principalmente, o aspecto da contratação de corpo docente e pessoal especializado, conforme a demanda das universidades corporativas, em contraste com a manutenção de corpo docente titulado em horário integral ou parcial nas instituições de ensino superior tradicionais.

Outro elemento incorporado à defesas das UCs e seus custos salienta a diferença entre as UCs e os antigos departamentos de Treinamento e Desenvolvimento (T \& D) existente nas empresas. Para Alperstedt (2001), os antigos departamentos de T\&D eram considerados centros de custos, com as UCs passaram a ser considerados como "um potencial centro de lucros, constituindo uma forma alternativa de captação de recursos financeiros para a empresa" (p. 75), visto que as empresas abrem seus cursos para o público externo, incluindo fornecedores. Segundo Alperstedt,

\footnotetext{
algumas das universidades corporativas extrapolam o oferecimento dos cursos de treinamento para além dos funcionários da empresa, estendendo-os à clientes, fornecedores, franqueados, outras empresas, e até mesmo à comunidade externa em geral. Vale lembrar que a referência aos clientes, engloba todos os intermediários no processo de venda, ou seja, revendedores, distribuidores, atacadistas e lojistas (2003).
}

As UCs implantadas no Brasil se mantêm em regime de parcerias para a formação e a certificação dos alunos. As parcerias representam uma 'troca de serviços', na qual todas as instituições parceiras ganham. As UCs ganham com a validação dos diplomas, enquanto as instituições de ensino superior aumentam o número de alunos. Dentre as parcerias citadas, 
vale destacar a Universidade do Hambúrguer da América Latina (UH), do grupo McDonald's, que mantém parceria com a Fundação Getúlio Vargas de São Paulo (FGV-SP), para desenvolver o curso de MBA aos funcionários da rede no Brasil. Esse programa, denominado Líderes do Século XXI, é inédito na corporação e trabalha a questão administrativa, técnica e comportamental, com 33 pessoas potencialmente capazes de se tornarem 'profissionais de ponta' (Idem). Para a Universidade do Hambúrguer do Brasil e da América Latina (Hamburger University), a parceria com a FGV é importante em função da necessidade que a universidade tem de complementar algumas áreas. "É um casamento feliz. Queremos sempre buscar novas parcerias". O grupo McDonald's investiu cerca de 7 milhões de reais para a construção da sede da Universidade que se localiza no município de Barueri, em São Paulo. O prédio tem quatro pavimentos e 3.542 metros quadrados de área construída. (TEIZEN, 2004 apud EDUCAÇÃO CORPORATIVA, 2004).

A Universidade do Hambúrguer é um exemplo de múltiplas parcerias o que significa, para eles, abrir as portas para outros parceiros a favor do capital intelectual, visto que não há resistência em relação a outras instituições a se tornarem parceiras. "Claro que o reconhecimento de uma universidade é importante, mas o que nos interessa é o currículo, o programa e o que elas podem nos oferecer" (TEIZEN, 2004 apud EDUCAÇÃO CORPORATIVA, 2004). A Universidade do Hambúrguer conta, como parceiras, escolas de inglês, a Universidade Paulista (UNIP), a Faculdade Senac. "A escolha do Senac foi imprescindível, porque nós estamos no Brasil inteiro e a faculdade nos acompanha. Fica fácil para gente. O que não podemos é deixar nossos clientes e ficar só em São Paulo" (Idem).

A Universidade do Hambúrguer foi criada em 1961 pela rede McDonald's e chegou ao Brasil em 1997. Na universidade, os cursos mais avançados são ministrados em São Paulo, ficando os demais a cargo das regionais da cadeia. Os cursos os cursos oferecidos envolvem formação de gerência, média e alta diretoria. "Incluimos treinamentos de operações, relações com a mídia, apresentação e marketing. Atuamos como se cada restaurante fosse uma escola primária, cada centro de treinamento regional uma instituição de segundo grau e a Universidade de Hambúrguer a terceira etapa da formação acadêmica ou terceiro grau" (INSTITUIÇÃO..., 2000). A Universidade do Hambúrguer oferece cursos em diferentes níveis: “franqueado da McDonald's desde 1992, o empresário [...] é doutor em 'hamburgolorogia' pela Universidade do Hambúrguer e professor do curso básico de operações para gerente de loja. 'Os assuntos abordados são os mais diversos possíveis e englobam conhecimentos na área de relacionamento com o cliente, liderança, contabilidade e equipamentos"” (INSTITUIÇÃO..., 2000). 
Um outro exemplo de 'casamento feliz' entre universidade corporativa e instituições de ensino superior é o caso da Universidade Unimed, que também conta com o apoio de Instituição de Ensino Superior para a certificação de cursos. Para a diretoria de Educação Coorporativa da Universidade Unimed, "a idéia é abrir o leque de treinamento para mais pessoas, o que não altera a qualidade do curso". Ele revela que não há uma exclusividade com os parceiros e tem planos para o futuro: "a intenção a médio e curto prazo é que possamos certificar os alunos pela Universidade Unimed". A busca de certificação de seus alunos seria a conquista da autonomia para essas 'universidades', o que é, para Alperstedt (2003), uma tendência das universidades norte-americanas, mas a certificação apresenta no Brasil uma série de restrições. Para ela, "a empresa vinculada à universidade corporativa tem o seu próprio negócio, sua área de atuação, por isso não vejo razão em passar a se dedicar a dois segmentos distintos, naquele em que já atua e em outro, o educacional, que pouco conhece".

No caso da Universidade Unimed, "em quatro anos de trabalho, foram treinados mais de 11000 profissionais". São aproximadamente 1400 alunos nos cursos de pósgraduação, distribuídos em 42 turmas em 15 estados. E mais de 7000 alunos em cursos de curta duração sobre temas diversos. O investimento anual para manutenção, segundo a Fundação Unimed, é de 640 mil reais, provenientes da contribuição dos 132 mantenedores (EDUCAÇÃO CORPORATIVA, 2004).

Um outro exemplo a ser citado é o Centro de Desenvolvimento Coca-Cola. Este Centro atende 16 fabricantes, a indústria Coca-Cola e um sistema integrado de empresas com 25 mil funcionários. A Universidade Corporativa não foi oficialmente criada, mas o Centro oferece treinamento e cursos de especialização, também, em parceria com a Fundação Getúlio Vargas. Para Dóris d'Alincourt Fonseca, diretora do Centro de Desenvolvimento do Sistema Coca-Cola, o objetivo dos treinamentos realizados é mostrar ao funcionário que a educação está sendo valorizada pela corporação e, para ela, a nomenclatura Universidade Corporativa é apenas conceitual. (FONSECA, 2004 apud EDUCAÇÃO CORPORATIVA, 2004).

Para Marisa Eboli, da Faculdade de Economia e Administração da USP, as parcerias são fundamentais, e o diferencial para as instituições estabelecerem as parcerias está, segundo ela, "na capacidade que a instituição tem de agregar valor aos programas educacionais das empresas. Os casos de UC no Brasil apontam muitos outros parceiros além de USP e FGV, tais como: Fundação Dom Cabral, IBMEC, PUC, Sebrae, ITA, Unicamp, FAAP, Anhembi Morumbi etc. Ou seja, mais do que o nome, vale a competência da 
instituição em agregar valor à parceria" (EBOLI, 2004 apud EDUCAÇÃO CORPORATIVA, 2004).

No que se refere ao espaço físico, muitas universidades corporativas contam com instalações próprias, e outras contam com as instalações de instituições de ensino superior tradicionais em regime de parceria. Nos dois casos, elas podem atuar de maneira centralizada, deslocando todos os empregados para um mesmo local ou, de forma descentralizada, contando com vários locais distribuídos entre vários pontos no mesmo país ou no mundo. Segundo Alperstedt (2003), além da Universidade do Hambúrguer, a Motorola University é outro exemplo de universidade corporativa que conta com instalações próprias, espalhadas ao redor do mundo, incluindo a unidade instalada no Brasil, no município de Jaguariúna, em São Paulo. Também contam com instalações físicas próprias a Universidade Academia de Serviços Accor, do grupo Accor, que tem um campus instalado em Campinas, São Paulo e a Boston School, do BankBoston, com sede em São Paulo, capital.

A Universidade Embraer, analisada por Ferreira (2002), também conta com sede fixa, no município de São José dos Campos, distrito de Eugenio de Melo. No entanto, segundo ele, manter sede fixa não é uma constante nestas instituições visto que, em muitos casos, há o conceito de universidade corporativa com estrutura virtual, como é o caso da Brahma - as aulas são realizadas por meio de videoconferência e os profissionais participam dos cursos à distância em suas próprias unidades de trabalho. Na América Latina, vale destacar o caso do Centro Internacional de Educación y Desarrollo - CIED da Petróleos de Venezuela S.A. - PDVSA que tem sua sede em Caracas e conta com mais 12 centros educacionais espalhados pela Venezuela Alperstedt (2003).

Ainda segundo Alperstedt (2003), algumas universidades corporativas sublocam espaços em hotéis, centros de convenções e similares, como é o caso da Visa Training da Visa do Brasil. Outras universidades corporativas não contam com qualquer tipo de arranjo físico concreto, pois estão baseadas em redes eletrônicas, independentes de espaço físico, constituindo o que se convencionou denominar de organizações virtuais. No Brasil, são exemplos de universidades corporativas virtuais a Unite da Telemar, a Escola Amil e a Universidade Brahma (ALPERSTEDT, 2003 e ALPERSTEDT, 2001, p, 65). Pode-se perceber que a definição do espaço físico, que irá abrigar os cursos das universidades corporativas, não é um obstáculo ao funcionamento e crescimento das mesmas. Entretanto outros elementos são considerados problemas e, dentre eles, destaca-se o reconhecimento dos créditos cursados, a validação dos cursos e outorga de diplomas. 
Alperstedt (2003), citando pesquisa desenvolvida por Meister (1999), revela que cerca de $25 \%$ das universidades corporativas oferecem créditos universitários e $40 \%$ esperam começar a criar programas que garantam créditos. "Esses créditos têm validade a partir de uma parceria desenvolvida com uma instituição de ensino superior tradicional, que, a partir de critérios negociados, assume a validade dos programas desenvolvidos pelas universidades corporativas como créditos reconhecidos para a obtenção de um diploma". (ALPERSTEDT, 2003). Para esta autora, assim como para Eboli (2004),

a parceria entre as universidades corporativas e as instituições de ensino superior tradicionais prevê uma troca de serviços entre ambas. As universidades corporativas ganham com a validação dos créditos na obtenção de um diploma, além da experiência dos docentes da instituição. E a instituição de ensino, por sua vez, tem aumentado o seu potencial de captação de alunos, em função dos incentivos para que os empregados dêem continuidade aos seus estudos, além do ganho pela aproximação com a realidade organizacional das empresas (ALPERSTEDT, 2003).

Segundo ela, essas parcerias têm permitido às universidades corporativas desenvolverem-se por meio de instituições de ensino superior tradicionais, além de cursos tradicionais, cursos inovadores conferindo diplomas de graduação em 'serviço ao consumidor' e cita, no Brasil, o caso da Enterprise Resource Planning - ERP' - Universidade Datasul e Universidade do Estado de Santa Catarina (UDESC). E afirma que, como as universidades corporativas não têm o poder de chancela de diplomas, "esse é, com freqüência, um dos estímulos mais significativos ao estabelecimento de parcerias" (Idem). Ainda segundo esta autora, no Brasil, a Boston School, universidade corporativa do BankBoston, está buscando acreditação ${ }^{15}$ de seu MBA junto a The International Association for Management Education AACSB, que é um órgão de acreditação americano.

As críticas tecidas às universidades 'convencionais' ou 'tradicionais', nos autores pesquisados, denotam aspectos contraditórios e, dentre eles, merece destaque também o que se refere ao corpo docente. Segundo Alperstedt (2003), a política de contratação dos professores para ministrar os cursos nas universidades corporativas é variável:

algumas universidades corporativas entendem que apenas professores universitários titulados podem ministrar aulas, outras utilizam executivos da empresa e/ou consultores externos como professores, e outras ainda valemse dos próprios profissionais da empresa que submetidos a um treinamento e preparação pela instituição de ensino a qual estão vinculados em regime de

\footnotetext{
15 "Do inglês accreditation, prática realizada nos Estados Unidos para avaliação das instituições educacionais e dos programas por elas oferecidos. Não se confunde com os termos credenciamento e reconhecimento utilizados no Brasil" (ALPERSTEDT, 2001, p. 21-22).
} 
parceria, obtiveram certificado de professor-adjunto ou equivalente (ALPERSTEDT, 2003).

Para ela, algumas destas definições, por parte das universidades corporativas, vão favorecer ou não o estabelecimento de parcerias junto às instituições de ensino superior tradicionais e, no caso da opção por professores titulados para ministrar cursos nas universidades corporativas, "embora haja possibilidade de contratação ad hoc de professores de diferentes instituições de ensino, a tendência é de busca de parcerias junto a estas instituições, a fim de facilitar o processo de contratação de professores, assim como reduzir os custos deste processo" (Idem).

A utilização ou 'aproveitamento' de profissionais da empresa, que possuem qualificação no quadro docente das universidades corporativas, é percebido por Ferreira (2002) como uma característica "interessante e ao mesmo tempo reveladora”, sendo isto também incentivo aos executivos para se envolverem no "desenvolvimento dos empregados". Para isto, há orientação e treinamento dos executivos para que possam exercer o papel de professor. "Desta forma, o executivo enquanto treinador reforça o seu compromisso com a empresa, dá o exemplo e, acima de tudo, estimula e lidera o processo de mudanças” (p. 2).

Mesmo questionando a qualidade na formação dos profissionais, realizada pelas universidades 'convencionais', parte-se deste conhecimento para a seleção de alunos para as universidades corporativas, como é o caso da Universidade Embraer, que tem por objetivo selecionar engenheiros de diferentes especialidades, egressos "das principais universidades do país, com até dois anos de formado" (FERREIRA, 2002, p. 5). Entretanto, mesmo sendo “egressos das principais universidades do país", os candidatos a uma vaga na Universidade Embraer - e conseqüentemente à empresa Embraer, são submetidos a um processo de seleção que ocorre em um "nível altamente exigente, através de exames técnicos escritos e entrevistas individuais, processo este realizado em diversas cidades brasileiras" (Idem). Tal exigência se justifica, segundo ele, porque "os selecionados serão incluídos no programa de educação corporativa com competências e tecnologia atual EMBRAER, preparando-os para os desafios de implantação de novas tecnologias e novos desafios da empresa" (Idem). A exigência de um público-alvo recém graduado (até dois anos) justifica-se visto que tem, segundo o autor, uma "formação adaptável".

A utilização da mão-de-obra da própria empresa não é a única no que se refere ao corpo docente. Para as empresas que criam suas próprias universidades, as universidades brasileiras 'tradicionais' não dão conta de uma formação voltada para as exigências do 
mercado, mas contraditoriamente vão até elas buscarem os serviços de "professores renomados" para contratação ou para parcerias.

As universidades corporativas têm buscado estabelecer parcerias com universidades tradicionais e segundo Alperstedt (2001), este é um aspecto que beneficia todas as instituições parceiras, porque, no que se refere às universidades corporativas, a motivação pode ocorrer devido a: a) possibilidade de validação das disciplinas cursadas; b) possibilidade de outorga de diploma; c) ausência de espaço físico disponível; d) necessidade de docentes com conhecimento especializado; e) necessidade de docentes com experiência didática; f) necessidade de fundir o currículo com a cultura corporativa; g) interesse na formação de mãode-obra especializada na comunidade (p. 136-137).

Por outro lado, do ponto de vista das instituições de ensino 'tradicionais', o estabelecimento de parcerias também é representado por Alperstedt como uma série de vantagens: a) aproximação com a realidade organizacional das empresas; b) incremento das possibilidades de pesquisa; c) aumento da arrecadação de recursos financeiros; d) aumento do potencial de captação de alunos (p. 137).

Ao realizar estudo sobre quatro universidades corporativas no Brasil (Universidade Datasul - DATASUL; Motorola University - MOTOROLA; Visa Training - VISA e Boston School - BANKBOSTON), Alperstedt (2001) afirma que, dentre estas quatro universidades, somente a Visa não adota o sistema de parcerias, tendo em vista "que o conhecimento específico objetivado não está presente nessas instituições [...] é a empresa, no caso a Visa, que detém esse conhecimento específico" (p. 313).

Um aspecto que merece destaque refere-se à Motorola University que estabelecu parceria com a Fundação Vanzolini, vinculada ao corpo docente da Escola Politécnica da Universidade de São Paulo (USP), e, segundo informações da Motorola foi mais fácil para eles trabalharem com a Vanzolini porque as instituições de ensino superior estão presas aos seus processos e possuem objetivos que não coadunam com os objetivos da empresa (ALPERSTEDT, 2001, p. 212-213). A Boston School, por sua vez, estabeleceu parcerias com a USP por meio da Fundação Instituto de Administração (FIA) e a Universidade Datasul, com a Universidade do Estado de Santa Catarina (UDESC), Universidade Federal de Santa Catarina (UFSC) e com a Universidade Estadual do Rio de Janeiro (UERJ).

Buscando analisar se as universidades corporativas e as instituições de ensino superior 'tradicionais' estariam em situações de parcerias ou competição, Alperstedt (2001) entrevistou dirigentes das quatro universidades por ela pesquisadas e verificou as três universidades corporativas, que mantêm convênios com instituições universitárias regulares, 
(DATASUL, MOTOROLA, BANKBOSTON), defendem que há cooperação e não situações de competição entre as mesmas. Somente a Visa acredita que as corporativas competem com as demais instituições de ensino superior 'tradicionais'.

Ainda com o objetivo de verificar a situação de competição ou cooperação, a autora entrevistou, também, representantes de diferentes instituições educacionais, dentre elas: Associação Brasileira de Mantenedoras de Ensino Superior (ABMES); Associação Nacional de Universidades Particulares (ANUP); Conselho de Reitores das Universidades Brasileiras (CRUB); Sindicato das Entidades Mantenedoras do Estado de São Paulo (SEMESP); Faculdade de Economia, Administração e Contabilidade da Universidade de São Paulo (FEA/USP); Escola Politécnica da Universidade de São Paulo (Poli/USP).

Nas entrevistas realizadas pela autora foi possível perceber que estas instituições têm pouco conhecimento sobre o que são as universidades corporativas e pode-se perceber, em sua maioria, que existe competição entre as corporativas e as 'tradicionais', conforme quadro abaixo:

\section{Quadro 6}

Universidades Corporativas: opinião dos órgãos representantes e de instituições de ensino superior

\begin{tabular}{|c|c|c|c|c|c|}
\hline & $\begin{array}{c}\text { CONHECIMENTO } \\
\text { ACERCA DAS } \\
\text { UNIVERSIDADES } \\
\text { CORPORATIVAS }\end{array}$ & $\begin{array}{l}\text { CONHECIMENTO } \\
\text { ACERCA DAS } \\
\text { PARCERIAS } \\
\text { ESTABELECIDADAS } \\
\end{array}$ & $\begin{array}{c}\text { INTERESSE NO } \\
\text { ESTABELECIMENTO } \\
\text { E/OU RENOVAÇÃO } \\
\text { DESTAS PARCERIAS } \\
\end{array}$ & $\begin{array}{c}\text { RAZÕES QUE } \\
\text { MOTIVAM ESSE } \\
\text { DIRECIONAMENTO }\end{array}$ & $\begin{array}{c}\text { COMPETIÇÃO } \\
\text { OU } \\
\text { COOPERAÇÃO }\end{array}$ \\
\hline ABMES & não & não & $\operatorname{sim}$ & $\begin{array}{c}\text { consistência } \\
\text { profissional na } \\
\text { prestação de serviços } \\
\text { educacionais }\end{array}$ & competição \\
\hline CRUB & superficial & $\begin{array}{l}\text { sim, porém não } \\
\text { exatamente com } \\
\text { universidades } \\
\text { corporativas }\end{array}$ & $\operatorname{sim}$ & $\begin{array}{c}\text { serviços educacionais } \\
\text { de qualidade } \\
\text { prestados pelas } \\
\text { empresas }\end{array}$ & cooperação \\
\hline ANUP & superficial & $\begin{array}{l}\text { sim, porém não } \\
\text { exatamente com } \\
\text { universidades } \\
\text { corporativas } \\
\end{array}$ & $\operatorname{sim}$ & $\begin{array}{l}\text { serviços educacionais } \\
\text { de qualidade } \\
\text { prestados pelas IES }\end{array}$ & competição \\
\hline SEMESP & superficial & $\begin{array}{l}\text { sim, porém não } \\
\text { exatamente com } \\
\text { universidades } \\
\text { corporativas }\end{array}$ & $\operatorname{sim}$ & $\begin{array}{c}\text { redução de custos nas } \\
\text { empresas, mais alunos } \\
\text { nas instituições de } \\
\text { ensino }\end{array}$ & competição \\
\hline FEA/USP & superficial & $\begin{array}{l}\text { sim, porém não } \\
\text { exatamente com } \\
\text { universidades } \\
\text { corporativas }\end{array}$ & $\operatorname{sim}$ & $\begin{array}{l}\text { serviços educacionais } \\
\text { de qualidade } \\
\text { prestados pelas } \\
\text { empresas }\end{array}$ & competição \\
\hline POLIUSP & superficial & sim & sim & $\begin{array}{l}\text { serviços educacionais } \\
\text { de qualidade } \\
\text { prestados pelas IES }\end{array}$ & $\begin{array}{l}\text { competição/ } \\
\text { cooperação }\end{array}$ \\
\hline
\end{tabular}

Fonte: ALPERSTEDT, 2001, p. 371. 
Para os defensores das universidades corporativas, as universidades 'tradicionais' devem se adaptar ao novo modelo de qualificação do trabalhador. Alperstedt (2001), citando Drucher (1992), afirma que

nos próximos 50 anos, escolas e universidades vão mudar mais drasticamente do que o fizeram em todos os seus anos de existência; e o que vai produzir essas mudanças são, em parte as novas tecnologias a serviço do aprendizado, e em parte, as demandas da sociedade do conhecimento as quais transformaram o aprendizado num processo contínuo e permanente ao longo da vida profissional (ALPERSTEDT, 2001, p. 106).

Para a autora, o prazo estipulado por Drucher (1992) é muito longo, visto que, segundo ela, as transformações nas instituições de ensino superior e a "redefiniçãa" do mercado educacional, com as aulas virtuais, já estão presentes na atualidade redesenhando o perfil das instituições. Contrapondo esta idéia propagada por Drucker e reafirmada por Alperstedt, Marcovitch (2002) afirma que Drucker estava equivocado quando prognosticou, décadas atrás, o futuro das universidades. Segundo ele, "foi um prognóstico superficial, prematuro e pessimista que infelizmente não se realizou. Ao contrário do que ele previu, a tecnologia de informação não substituiu o convívio presencial na formação universitária. A pesquisa, a experimentação e a aprendizagem continuam dependendo bastante da freqüência presencial” (MARCOVITCH, 2002, p. 9).

Nas análises sobre os modelos de universidades está clara a diferença entre as universidades corporativas e as universidades acadêmicas. Para Quartiero e Cerny (2005) as comparações entre os dois modelos deixam evidentes suas distinções e perspectivas formativas sendo necessário estabelecer os limites de uma de outra agência formadora. Ao se evidenciar a importância de uma e outra instituição educacional verifica-se que "a universidade corporativa só tem sucesso quando se apóia na competência formativa da universidade acadêmica" (p. 39).

\section{Considerações finais}

Não se pode ignorar que as universidades corporativas representam um espaço a mais para a atuação da empresa. Conforme disseram Cavalcanti e Gomes (s/d), citando Paul Strassman, "as empresas que continuam a ter suas vantagens competitivas dependentes de recursos naturais, trabalho e capital financeiro estarão cada vez mais vulneráveis frente às 
empresas baseadas em conhecimento" (p. 13). E mesmo não podendo ser efetivamente consideradas como universidades, as Corporativas engrossam as fileiras no número de instituições a ministrarem o ensino superior no país.

\section{Fontes bibliográficas}

ALPERSTEDT, Cristina. As universidades corporativas no contexto do ensino superior. Tese (Doutorado em Administração). Departamento de Administração. Faculdade de Economia, Administração e Contabilidade. Universidade de São Paulo. São Paulo, 2001.

, Educação corporativa: estratégias de promoção da gestão do conhecimento. Aprender. Jan./fev., 2003. Disponível em <http://www.aprendervirtual.com> - Acesso em 24/08/2004.

BIANCHETTI, Lucídio e QUARTIERO, Elisa Maria (Orgs.). Educação corporativa: mundo do trabalho e do conhecimento - aproximações. Santa Cruz do Sul: EDUNISC; São Paulo: Cortez, 2005.

BRAGA, Ryon. Centros de aprendizagem corporativa. Aprender - jan./fev./2004. Disponível em <http://www.aprendervirtual.com> - Acesso em 24/08/2004.

CAVALCANTI, Marcos e GOMES, Elizabeth. A sociedade do conhecimento e a política industrial brasileira. Disponível em: <http://www.desenvolvimento.gov.br/sitio/ sti/publicacoes/futAmaDilOportuniddades/futIndOpoDesafios.php>. Acesso em 10/10/2004, (s/d).

COSTA, Ana Cláudia A. da Costa. Educação corporativa: um avanço na gestão integrada do desenvolvimento humano. Rio de Janeiro: Qualitymark Ed., 2001. (Recursos Humanos; 13)

EBOLI, Marisa (coord.). Universidades corporativas: educação para as empresas do século XXI. São Paulo: Schmukler, 1999.

EDUCAÇÃO CORPORATIVA - Casamento feliz. Aprender, mar./abr., 2004. Disponível em <http://www.aprendervirtual.com> - Acesso em 24/08/2004.

EMBACHER, Airton. A educação nas empresas: do T\&D à universidade corporativa. Aprender - mar./abr., 2003a. Disponível em <http://www.aprendervirtual.com> - Acesso em 24/08/2004.

A nova economia e a gestão do conhecimento - Aprender - mai./jun., 2003b.

Disponível em <http://www.aprendervirtual.com> - Acesso em 24/08/2004.

FERREIRA, Paulo R. Gomes. Universidade corporativa: estudo de caso. Monografia apresentada à Universidade do Vale do Paraíba. São José dos Campos, 2002. Disponível em >http:/www.univap.br/biblioteca/hp_julho2002/Monografia\%20 Revisada\%20julho\%202002/ 018.pdf>. Acesso em 21/08/2004. 
FRIGOTTO, Gaudêncio. A educação e a crise do capitalismo real. 4. ed. São Paulo: Cortez, 2000 .

INSTITUIÇÃO ensina segredos do hambúrguer há 39 anos. Disponível em http://www2.uol.com.br/JC/_2000/1607/ec1607h.htm. Acesso em 08/04/2006.

MARCOVITCH, Jacques. A informação e o conhecimento. São Paulo Perspec. [online]. out./dez. 2002, vol.16, n. 4 p. 03-08. Disponível em: <http://www.scielo.br/scielo. Acesso em 29/05/2005.

MEISTER, J. C. Educação corporativa: a gestão do capital intelectual através das universidades corporativas. São Paulo: Makron Books, 1999.

QUARTIERO, Elisa Maria e CERNY, Rosely Zen. Universidade corporativa: uma nova faze da relação entre mundo do trabalho e mundo da educação. In.: BIANCHETTI, Lucídio e QUARTIERO, Elisa Maria (Orgs.). Educação corporativa: mundo do trabalho e do conhecimento - aproximações. Santa Cruz do Sul: EDUNISC; São Paulo: Cortez, 2005.

TEIXEIRA, Andréa. Universidades corporativas X educação corporativa: o desenvolvimento do aprendizado contínuo. Rio de Janeiro: Qualitymark Ed., 2001. (Recursos Humanos; 11) 